\title{
A simple umbelliferone based fluorescent probe for the detection of nitroreductase
}

\author{
Adam C. Sedgwick ${ }^{1}$, Alex Hayden ${ }^{2}$, Barry Hill ${ }^{2}$, Steven D. Bull ${ }^{1}$, Robert B. P. Elmes $(\bowtie)^{2}$, Tony D. James $(\bowtie){ }^{1}$ \\ 1 Department of Chemistry, University of Bath, Bath, BA2 7AY, UK \\ 2 Department of Chemistry, Maynooth University, Maynooth, Co. Kildare, Ireland
}

(C) Higher Education Press and Springer-Verlag GmbH Germany, Part of Springer Nature 2018

\begin{abstract}
A simple nitrobenzyl-umbelliferone (NCOU1) was synthesised containing a nitroreductase (NTR) trigger moiety. The presence of NTR, resulted in the fragmentation of the parent molecule and release of the highly emissive fluorophore umbelliferone via an NTR-catalyzed reduction of the nitro group. In the presence of the NTR enzyme, NCOU1 gave rise to a 5 -fold increase in fluorescence intensity at $455 \mathrm{~nm}$ and was selective for NTR over other reductive enzymes. These results indicate that NCOU1 can be used as a simple assay for the detection of NTR.
\end{abstract}

\section{Introduction}

Nitroreductase (NTR), a member of the family of flavincontaining oxidoreductases, is one of a series of biomarkers that have been shown to be significantly upregulated in cells under hypoxic stress [1,2]. Indeed, hypoxia, known to play a role in a number of diseases has gained considerable attention in recent times owing to its role in tumour development and resistance to therapy $[3,4]$. While a number of detection methods such as ${ }^{19} \mathrm{~F}$ NMR, positron emission tomography, single-photon emission computed tomography have been exploited to study hypoxia [5], the exact role played by NTR in tumour hypoxia remains elusive. Among the powerful tools available for NTR detection are synthetic small-molecular fluorescent probes owing to their high sensitivity, selectivity and high spatial and temporal resolutions [6-8]. Therefore, the selective fluorescent sensing of NTR has recently become a highly topical area of research [9-17].

Qian and co-workers have developed a number of probes for the detection of hypoxia in HeLa cells $[18,19]$

Received September 17, 2017; accepted November 17, 2017

E-mails: Robert.Elmes@mu.ie (Elmes R B P), T.D.James@bath.ac.uk (James T D) and Hecht and co-workers recently confirmed the presence of NTR in the mitochondria of mammalian cells using a highly sensitive cyanine based probe [20]. Ma and coworkers have described a number of fluorescent probes to enable the sensitive detection and quantification of NTR in both mammalian [21,22] and bacterial cells [23] while their most recent contribution described an example of an aggregation induced emission based probe for NTR [24]. We have developed a ratiometric probe based on the 2-nitroimidazole moiety and demonstrated that such an approach can be used for the facile monitoring of NTR activity in mammalian cells under reductive stress both by confocal microscopy and flow cytometry [25]. With our interest in developing fluorescent probes to monitor markers of biological significance [26-31]. We were inspired to explore and develop more fluorescent based systems for the detection of NTR and to gain a better understanding of the role played by NTR in hypoxia related cellular stress.

Our design centred around the coumarin moiety as a responsive fluorophore that could be 'triggered' upon reduction by NTR. We envisaged that our simple nitrobenzyl-umbelliferone probe (NCOU1), would give rise to a fragmentation of the parent molecule and release of the highly emissive fluorophore umbelliferone via the NTR-catalyzed reduction of the nitro group. Our design strategy is reinforced by the previously reported reduction of NCOU1 using $\mathrm{Zn} / \mathrm{AcOH}$ to produce a 'turn on' fluorescence response [32]. Our results clearly demonstrate the success of this approach, since treatment of NCOU1 with NTR gave rise to a 5-fold increase in emission intensity at $455 \mathrm{~nm}$ and was shown to be selective for NTR over other reductive enzymes.

\section{Results and discussion}

The synthesis of NCOU1 was a simple one step alkylation 


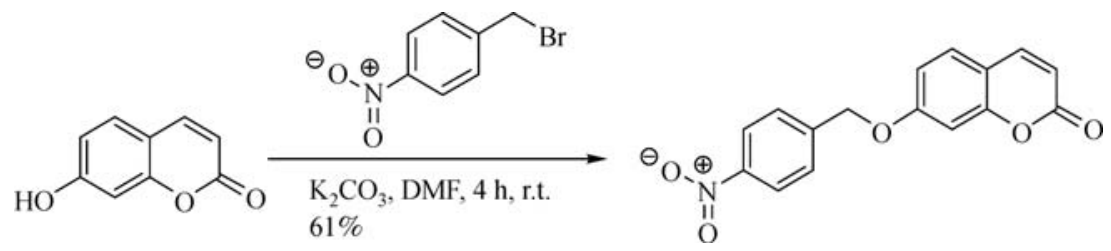

Scheme 1 Synthesis of NCOU1

of the commercially available umbelliferone using 4-nitrobenzyl bromide, $\mathrm{K}_{2} \mathrm{CO}_{3}$ and DMF (Scheme 1). The reaction proceeded cleanly and required minimal purification. NCOU1 was fully characterised using ${ }^{1} \mathrm{H}$ NMR, ${ }^{13} \mathrm{C}$ NMR, IR, UV/vis and mass spectrometry. All spectroscopic data was consistent with the formation of the desired compound (see electronic supplementary information (ESI)).

With NCOU1 in hand, the ability of the probe for the detection of NTR was evaluated. As illustrated in Fig. 1, under a UV lamp NCOU1 is non-fluorescent (a). The addition of NTR led to the reduction of the nitro functionality resulting in the elimination of the fluorescent umbelliferone (b). For comparative purposes, a solution containing umbelliferone was shown next to the two solutions (c). This observation was further confirmed using mass spectroscopic analysis (ESI Fig. S7).

Initially, NCOU1 was treated with a larger concentration of the enzyme NTR $(8 \mu \mathrm{g} / \mathrm{mL})$ with the required co-factor $\mathrm{NADH}(500 \mu \mathrm{mol} / \mathrm{L})$. As shown in Fig. 2 an increase in fluorescence intensity was observed over the course of $60 \mathrm{~min}$.

NCOU1 was shown to detect NTR in a dose-dependent manner. NTR $8 \mu \mathrm{g} / \mathrm{mL}$ resulted in the largest fluorescence response $>16$-fold. NCOU1 was also shown to detect NTR at concentrations as low as $1 \mu \mathrm{g} / \mathrm{mL}$ and at acidic, basic and neutral $\mathrm{pH}$ clearly demonstrating its ability to be used for biological applications shown in Fig. 3 (See Fig. $\mathrm{S} 3$ for $\mathrm{pH}$ experiment).

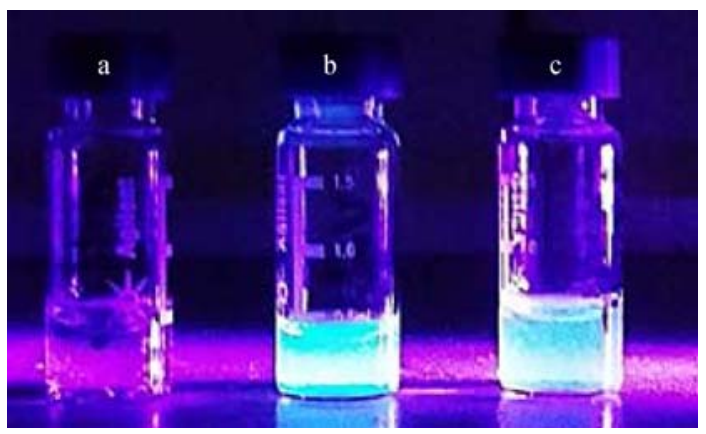

Fig. 1 Photograph of (a) NCOU1, (b) umbelliferone, and (c) NCOU1 + NTR

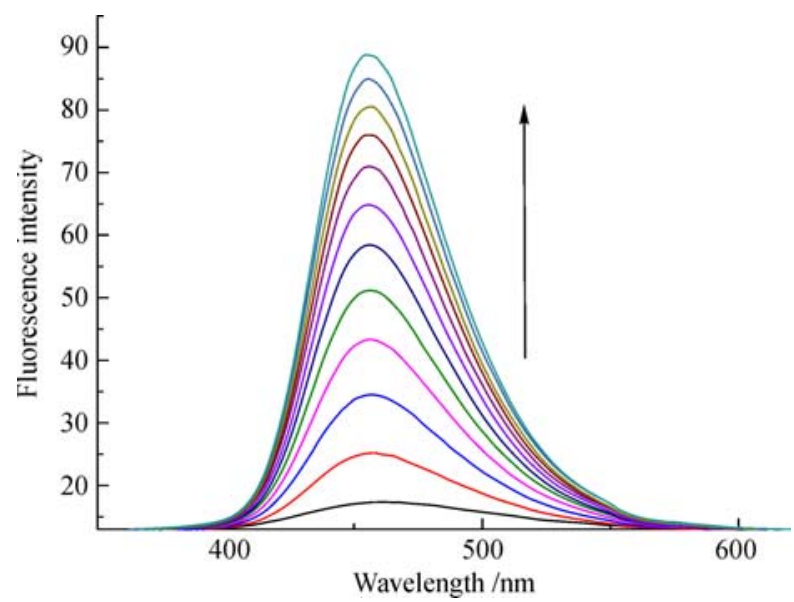

Fig. 2 Fluorescence spectra of NCOU1 $(10 \mu \mathrm{mol} / \mathrm{L})$ with the addition of nitroreductase $(8 \mu \mathrm{g} / \mathrm{mL})$ and NADH $(500 \mu \mathrm{mol} / \mathrm{L})$ and measured over $60 \mathrm{~min}$ in $10 \mathrm{mmol} / \mathrm{L}$ PBS (pH 7.4). $\lambda_{\text {ex }}=315 \mathrm{~nm}$

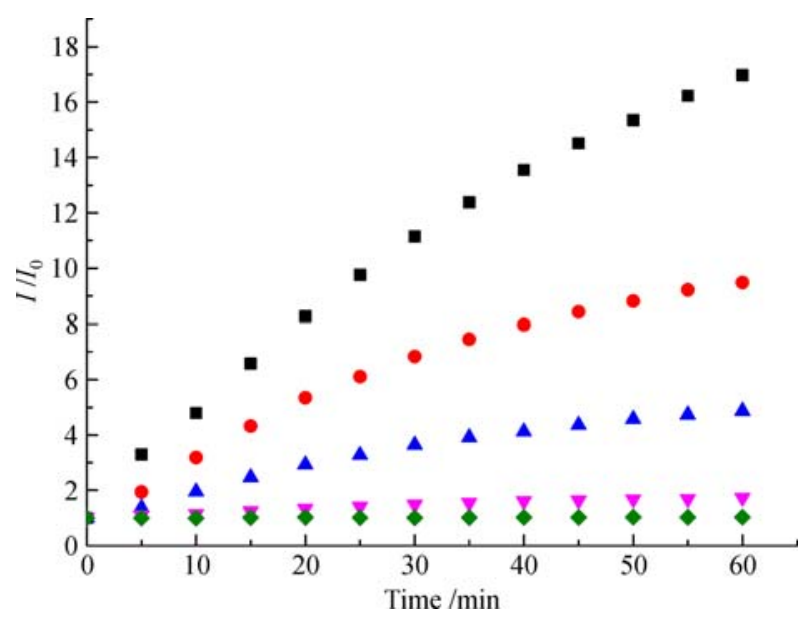

Fig. 3 Dose-response time curve of NCOU1 $(10 \mu \mathrm{mol} / \mathrm{L})$ with additions of nitroreductase $(0,0.5,1,4$ and $8 \mu \mathrm{g} / \mathrm{mL})$ and $\mathrm{NADH}$ $\left(500 \mu \mathrm{mol} / \mathrm{L}\right.$ in $10 \mathrm{mmol} / \mathrm{L}$ PBS (pH 7.4)). $\lambda_{\mathrm{ex}}=315 \mathrm{~nm}$

Due to the complexity of biological samples, the selectivity of NCOU1 towards another reductive enzyme, 
DT-diaphorase (hNQO1), was performed. DT-diaphorase is a cellular reductase that is widely distributed in all cellular environments including the cytosol, golgi complex, nucleus, mitochondrial membranes and endoplasmic reticulum, as well as in extracellular components [33] thus the ability to differenciate between such reductive enzymes is of the utmost importance. NCOU1 was shown to be highly selective towards NTR over DT-diaphorase as shown in Fig. 4. Moreover, in the presence of the known NTR inhibitor dicoumarol NCOU1 displayed a very minor fluorescence response to NTR clearly demonstrating its selectivity for the active NTR enzyme.

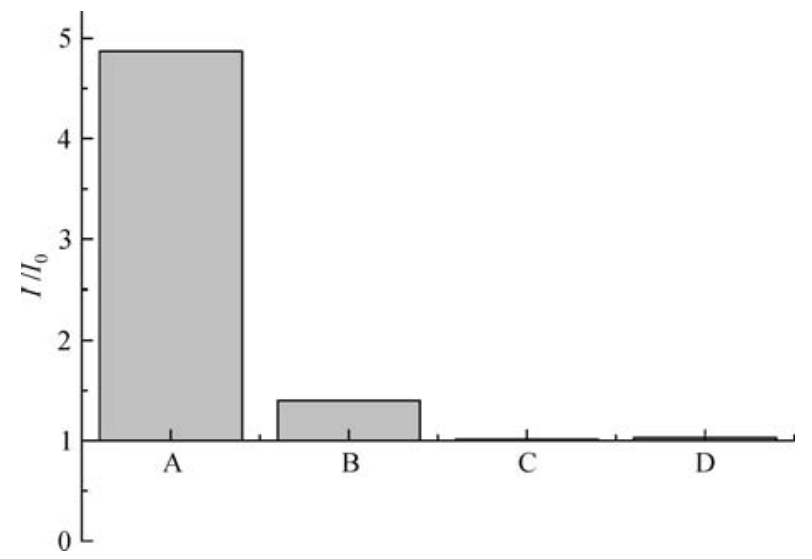

Fig. 4 Selectivity bar chart of NCOU1 $(10 \mu \mathrm{mol} / \mathrm{L})$ with addition of A (nitroreductase, $1 \mu \mathrm{g} / \mathrm{mL}$ ), B (nitroreductase and dicoumarol, $1 \mu \mathrm{g} / \mathrm{mL}$ ), C (DT-diaphorase, $1 \mu \mathrm{g} / \mathrm{mL}$ ) and D (blank). All measurements contained NADH $(500 \mu \mathrm{mol} / \mathrm{L})$ in $10 \mathrm{mmol} / \mathrm{L} \mathrm{PBS}$ $(\mathrm{pH} 7.4) \lambda_{\mathrm{ex}}=315 \mathrm{~nm}\left(\lambda_{\mathrm{em}}=455 \mathrm{~nm}\right)$

\section{Conclusions}

NCOU1 was synthesised by a simple one step alkylation of umbelliferone with 4-nitrobenzyl bromide. NCOU1 was shown to detect NTR at a low concentration $(1 \mu \mathrm{g} / \mathrm{mL})$. Fragmentation of the parent molecule and release of the highly emissive fluorophore umbelliferone via the NTRcatalyzed reduction of the nitro group. NCOU1 gave rise to a 5 -fold increase in emission intensity at $455 \mathrm{~nm}$ and was shown to have an excellent selectivity for NTR over other reductive enzymes. These results demonstrate the ability of NCOU1 to be used as a simple and cheap assay for the detection of NTR.

\footnotetext{
Acknowledgements We would like to thank the EPSRC and the University of Bath for funding. TDJ wishes to thank the Royal Society for a Wolfson Research Merit Award. ACS thanks the EPSRC for his studentship. RBPE acknowledges support funding from Maynooth University. NMR characterisation facilities were provided through the Chemical Characterisation and Analysis Facility (CCAF) at the University of Bath (www.bath.ac.uk/ccaf). All data supporting this study are provided as supplementary information accompanying this paper.
}

Electronic Supplementary Material Supplementary material is available in the online version of this article at https://doi.org/10.1007/s11705-017$1697-0$ and is accessible for authorized users.

\section{References}

1. Brown J M, Wilson W R. Exploiting tumour hypoxia in cancer treatment. Nature Reviews. Cancer, 2004, 4(6): 437-447

2. Wilson W R, Hay M P. Targeting hypoxia in cancer therapy. Nature Reviews. Cancer, 2011, 11(6): 393-410

3. Denny W A. Prodrug strategies in cancer therapy. European Journal of Medicinal Chemistry, 2001, 36(7-8): 577-595

4. Elmes R B P. Bioreductive fluorescent imaging agents: Applications to tumour hypoxia. Chemical Communications, 2016, 52(58): 8935-8956

5. Pacheco-Torres J, López-Larrubia $\mathrm{P}$, Ballesteros $\mathrm{P}$, Cerdán $\mathrm{S}$. Imaging tumor hypoxia by magnetic resonance methods. NMR in Biomedicine, 2011, 24(1): 1-16

6. Wu J, Kwon B, Liu W, Anslyn E V, Wang P, Kim J S. Chromogenic/fluorogenic ensemble chemosensing systems. Chemical Reviews, 2015, 115(15): 7893-7943

7. Yang Z, Cao J, He Y, Yang J H, Kim T, Peng X, Kim J S. Macro-/ micro-environment-sensitive chemosensing and biological imaging. Chemical Society Reviews, 2014, 43(13): 4563-4601

8. Qian X, Xiao Y, Xu Y, Guo X, Qian J, Zhu W. "Alive” dyes as fluorescent sensors: Fluorophore, mechanism, receptor and images in living cells. Chemical Communications, 2010, 46(35): 64186436

9. Xu K, Wang F, Pan X, Liu R, Ma J, Kong F, Tang B. High selectivity imaging of nitroreductase using a near-infrared fluorescence probe in hypoxic tumor. Chemical Communications, 2013, 49 (25): 2554-2556

10. Wan Q Q, Gao X H, He X Y, Chen S M, Song Y C, Gong Q Y, Li X $\mathrm{H}$, Ma H M. A cresyl violet-based fluorescent off-on probe for the detection and imaging of hypoxia and nitroreductase in living organisms. Chemistry, an Asian Journal, 2014, 9(8): 2058-2062

11. Yuan J, Xu Y Q, Zhou N N, Wang R, Qian X H, Xu Y F. A highly selective turn-on fluorescent probe based on semi-cyanine for the detection of nitroreductase and hypoxic tumor cell imaging. RSC Advances, 2014, 4(99): 56207-56210

12. Wong R H F, Kwong T, Yau K H, Au-Yeung H Y. Real time detection of live microbes using a highly sensitive bioluminescent nitroreductase probe. Chemical Communications, 2015, 51(21): 4440-4442

13. Xu J, Sun S, Li Q, Yue Y, Li Y, Shao S. A rapid response "turn-on" fluorescent probe for nitroreductase detection and its application in hypoxic tumor cell imaging. Analyst (London), 2015, 140(2): 574581

14. Zhou J, Shi W, Li L H, Gong Q Y, Wu X F, Li X H, Ma H M. A lysosome-targeting fluorescence off-on probe for imaging of nitroreductase and hypoxia in live cells. Chemistry, an Asian Journal, 2016, 11(19): 2719-2724

15. Jin C, Zhang Q, Lu W. Selective turn-on near-infrared fluorescence probe for hypoxic tumor cell imaging. RSC Advances, 2017, 7(30): 18217-18223 
16. Huang B, Chen W, Kuang Y Q, Liu W, Liu X J, Tang L J, Jiang J H. A novel off-on fluorescent probe for sensitive imaging of mitochondria-specific nitroreductase activity in living tumor cells. Organic \& Biomolecular Chemistry, 2017, 15(20): 4383-4389

17. Zhou Y, Bobba K N, Lv X W, Yang D, Velusamy N, Zhang J F, Bhuniya S. A biotinylated piperazine-rhodol derivative: A 'turn-on' probe for nitroreductase triggered hypoxia imaging. Analyst (London), 2017, 142(2): 345-350

18. Cui L, Zhong Y, Zhu W, Xu Y, Du Q, Wang X, Qian X, Xiao Y. A new prodrug-derived ratiometric fluorescent probe for hypoxia: High selectivity of nitroreductase and imaging in tumor cell. Organic Letters, 2011, 13(5): 928-931

19. Cai Q, Yu T, Zhu W, Xu Y, Qian X. A turn-on fluorescent probe for tumor hypoxia imaging in living cells. Chemical Communications, 2015, 51(79): 14739-14741

20. Chevalier A, Zhang Y, Khdour O M, Kaye J B, Hecht S M. Mitochondrial nitroreductase activity enables selective imaging and therapeutic targeting. Journal of the American Chemical Society, 2016, 138(37): 12009-12012

21. Li Z, He X, Wang Z, Yang R, Shi W, Ma H. In vivo imaging and detection of nitroreductase in zebrafish by a new near-infrared fluorescence off-on probe. Biosensors \& Bioelectronics, 2015, 63: $112-116$

22. Li Z, Li X, Gao X, Zhang Y, Shi W, Ma H. Nitroreductase detection and hypoxic tumor cell Imaging by a designed sensitive and selective fluorescent probe, 7-[(5-nitrofuran-2-yl)methoxy]-3Hphenoxazin-3-one. Analytical Chemistry, 2013, 85(8): 3926-3932

23. Li Z, Gao X, Shi W, Li X, Ma H. 7-((5-Nitrothiophen-2-yl) methoxy)-3H-phenoxazin-3-one as a spectroscopic off-on probe for highly sensitive and selective detection of nitroreductase. Chemical Communications, 2013, 49(52): 5859-5861

24. You X, Li L, Li X, Ma H, Zhang G, Zhang D. A new tetraphenylethylene-derived fluorescent probe for nitroreductase detection and hypoxic-tumor-cell imaging. Chemistry, an Asian Journal, 2016, 11(20): 2918-2923

25. Ao X, Bright S A, Taylor N C, Elmes R B P. 2-Nitroimidazole based fluorescent probes for nitroreductase; monitoring reductive stress in cellulo. Organic \& Biomolecular Chemistry, 2017, 15(29): 61046108

26. Sedgwick A C, Sun X L, Kim G, Yoon J, Bull S D, James T D. Boronate based fluorescence (ESIPT) probe for peroxynitrite. Chemical Communications, 2016, 52(83): 12350-12352

27. Sun X, Xu Q, Kim G, Flower S E, Lowe J P, Yoon J, Fossey J S, Qian X, Bull S D, James T D. A water-soluble boronate-based fluorescent probe for the selective detection of peroxynitrite and imaging in living cells. Chemical Science (Cambridge), 2014, 5(9): 3368-3373

28. Gu K Z, Xu Y S, Li H, Guo Z Q, Zhu S J, Zhu S Q, Shi P, James T $\mathrm{D}$, Tian $\mathrm{H}$, Zhu W H. Real-time tracking and in vivo visualization of beta-galactosidase activity in colorectal tumor with a ratiometric near-infrared fluorescent probe. Journal of the American Chemical Society, 2016, 138(16): 5334-5340

29. Li M, Wu X M, Wang Y, Li Y S, Zhu W H, James T D. A nearinfrared colorimetric fluorescent chemodosimeter for the detection of glutathione in living cells. Chemical Communications, 2014, 50 (14): 1751-1753

30. Sedgwick A C, Chapman R S L, Gardiner J E, Peacock L R, Kim G, Yoon J, Bull S D, James T D. A bodipy based hydroxylamine sensor. Chemical Communications, 2017, 53(75): 10441-10443

31. Sedgwick A C, Han H, Gardiner J E, Bull S D, He X P, James T D. Long-wavelength fluorescent boronate probes for the detection and intracellular imaging of peroxynitrite. Chemical Communications, 2017, 53(95): 12822-12825

32. Matikonda S S, Fairhall J M, Tyndall J D A, Hook S, Gamble A B. Stability, kinetic, and mechanistic investigation of 1,8-self-immolative cinnamyl ether spacers for controlled release of phenols and generation of resonance and inductively stabilized methides. Organic Letters, 2017, 19(3): 528-531

33. Kwon N, Cho M K, Park S J, Kim D, Nam S J, Cui L, Kim H M, Yoon J. An efficient two-photon fluorescent probe for human NAD (P)H: Quinone oxidoreductase (hNQO1) detection and imaging in tumor cells. Chemical Communications, 2017, 53(3): 525-528 